\title{
Cirsium brevicaule A. GRAY leaf inhibits adipogenesis in 3T3-L1 cells and C57BL/6 mice
}

\author{
Masashi Inafuku', Ruwani N Nugara ${ }^{1,2}$, Yasuo Kamiyama³ ${ }^{3}$ Itsuki Futenma', Ayako Inafuku and Hirosuke Oku*
}

\begin{abstract}
Background: Various flavonoids obtained from the genus Cirsium have been reported to exhibit beneficial effects on health. The present study evaluated the antiobesity effects of Cirsium brevicaule A. GRAY leaf (CL) by using 3T3-L1 cells and C57BL/6 mice that were fed a high-fat diet (HFD).

Methods: Dried CL powder was serially extracted with solvents of various polarities, and these extracts were tested for antiadipogenic activity using 3T3-L1 adipocytes. Mice were fed experimental HFD supplemented with dried CL powder for 4 wk. Lipid levels and mRNA levels of genes related to lipid metabolism were determined in 3T3-L1 adipocytes and the white adipose tissue (WAT) and liver of mice fed on a HFD.

Results: Treatment of 3T3-L1 adipocytes with a hexane extract of CL significantly reduced cellular lipid accumulation and expression of the fatty acid synthase (FASN) gene. Dietary CL reduced the serum levels of nonesterified fatty acids in HFD-fed mice. Significant decreases in subcutaneous WAT weight and associated FASN gene expression were observed in the mice fed the experimental $C L$ diet. Dietary $C L$ also reduced the hepatic lipid and serum levels of a hepatopathic indicator in the HFD-fed mice. A significant reduction in mRNA levels of FASN and HMG-CoA reductase were observed in the livers of the $C L$-diet group. Dietary $C L$, on the other hand, increased in the hepatic mRNA levels of genes related to $\beta$-oxidation, namely peroxisome proliferator-activated receptor $a$, calnitine palmitoyltrasferase $1 \mathrm{~A}$, and uncoupling protein 2. Expression of the insulin receptor gene was also significantly increased in the livers of mice-fed the $C L$ diet.
\end{abstract}

Conclusions: The present study therefore demonstrated that $\mathrm{CL}$ suppresses lipid accumulation in the WAT and liver partly through inhibiting mRNA levels of FASN gene and enhancing the lipolysis-related gene expression.

Keywords: Cirsium brevicaule A. GRAY, Anti-adipogenesis, Obesity, Non-alcoholic fatty liver disease

\section{Background}

Obesity, a natural consequence of over-nutrition and irregular living habits, contributes to the pathogenesis of metabolic syndrome. Metabolic syndrome, which comprises a cluster of metabolic abnormalities such as hyperlipidemia, type 2 diabetes mellitus (T2DM), and hypertension, is a widespread and an increasingly prevalent disease in industrialized countries, and it has contributed to an increase in cardiovascular morbidity and mortality $[1,2]$. Nonalcoholic fatty liver disease (NAFLD) is also often associated with metabolic syndrome [3,4]. Several therapeutic agents have been developed for treating obesity by reducing nutrient absorption [5] or by

\footnotetext{
* Correspondence: okuhiros@comb.u-ryukyu.ac.jp

${ }^{1}$ Center of Molecular Biosciences, Tropical Biosphere Research Center, University of the Ryukyus, 1 Senbaru, Nishihara, Okinawa 903-0213, Japan Full list of author information is available at the end of the article
}

enhancing thermogenesis and lipid turnover [5,6]. However, practical use of these drugs has been hampered by their side effects and because of the rebound weight, which is gained upon termination of these therapies. In this context, it has been considered that supplementation of the daily diet with natural anti-obesity agents would be effective for managing obesity, as well as calorie control and exercise. From viewpoint of safety, the medicinal plants and their active compounds merit investigation for development of natural antiobesity agents.

During recent decades, many studies reported the beneficial effects of flavonoids on health, and these effects were either dependent or independent of their antioxidant activities. Increasing evidence indicates that flavonoid-rich food, beverages, and extracts, as well as pure flavonoids, could ameliorate the symptoms of metabolic syndrome 
and its associated diseases [7]. Various flavonoids have been isolated as naturally occurring compounds from the genus Cirsium [8,9]. It was reported that pectolinarin and 5,7-dihydroxy-6,4'-dimethoxyflavone (DDMF) isolated from C. japonicum DC inhibits the growth of implanted tumors and promotes innate immunity in mice [10]. Further, these studies showed that flavonoids enhance the adipocyte differentiation and glucose uptake in 3T3-L1 cells [11] and demonstrated the antidiabetic activities of pectolinarin and DDMF in rats in which diabetes was induced by streptozotocin and a highcarbohydrate/high-fat diet [12]. The crude extracts of $C$. oligophyllum reduced the weight of subcutaneous and visceral white adipose tissue (WAT) weights in rats [13]. A significant hypoglycemic effect of $C$. pascuarense was shown in alloxan-induced diabetes [14]. C. brevicaule A. GRAY (CBAG), which is a wild perennial herb, grows in rocky gravels or forest margins along maritime coastlines [15], and is distributed in southern-Japan and Taiwan. Its leaves, stems and roots are traditionally used as not only a food stuff but also as herbal medicine in the Okinawa Islands and Amami Islands of Japan. However, no scientific data on the biological activities of CBAG are available. We therefore evaluated the biological activities of CBAG pertaining to metabolic syndrome. This study aimed to characterize the CBAG leaf $(\mathrm{CL})$ as an antiobesity agent by testing its activities in vitro tissue cultures and an in vivo animal model.

\section{Materials and methods}

\section{Preparation of CBAG leaf powder and extracts}

The CBAG that was used in this study was harvested on Tokunoshima Island in Kagoshima Prefecture, Japan. The freeze-dried and ground powder of CL was generously provided by Tokunoshima-cho (Kagoshima, Japan). The CL powder was analyzed by Japan Food Research Laboratories (Tokyo, Japan) and the nutrient composition was found to be as follows: carbohydrate, $12.7 \%$; fiber, $37.8 \%$; mineral 19.9\%; protein, 19.1\%; fat, 5.3\%; and moisture, $5.2 \%$. The dried-CL powder was serially extracted by incubation with 10 volumes of hexane, chloroform, ethanol and water for $2 \mathrm{~h}$ at $37^{\circ} \mathrm{C}$. The filtrates were evaporated or freeze-dried in vacuo, and stored at $-80^{\circ} \mathrm{C}$ until use. The dried extracts were dissolved in dimethyl sulfoxide at $25 \mathrm{mg} / \mathrm{mL}$ and filter-sterilized before use. The total phenolic contents of the serial extracts from the CL were measured using the Folin-Denis assay method as previously reported [16]. The phenolic contents were expressed in chlorogenic acid equivalents (mg CA/g extract).

\section{Cell culturing and treatment}

3T3-L1 preadipocytes were purchased from the American Type Culture Collection (VA, USA). 3T3-L1 cells were maintained in DMEM containing $10 \%$ calf serum at $37^{\circ} \mathrm{C}$ in a humidified atmosphere of $5 \% \mathrm{CO}_{2}$. Complete confluence of the cells was avoided before initiating differentiation. For adipogenesis, confluent cells were maintained for another $2 \mathrm{~d}$. And then differentiation was induced with standard differentiation procedure for $2 \mathrm{~d}$ in the presence of the CL extracts as mentioned previously [17]. The cells were re-fed with DMEM containing $10 \%$ FBS supplemented with $10 \mu \mathrm{g} / \mathrm{mL}$ human insulin and $50 \mu \mathrm{g} / \mathrm{mL}$ CL extract for $4 \mathrm{~d}$. Cell viability was measured using MTS assay to test the cytotoxic effects of the treatment on the 3T3-L1 cells.

\section{Measurement of lipid accumulation in cultured adipocytes}

To evaluate the effect of each CL extract on lipid accumulation, the cultured 3T3-L1 cells were stained with Oil Red O using a standard protocol, and their lipid droplets were observed under a microscope. Cellular lipid was extracted and purified by using the method of Bligh and Dyer [18], and intracellular triglyceride (TG) content was quantified using a commercial enzymatic kit as described below. The cellular protein content was determined using a Quant-iT protein assay kit (Life technologies, CA, USA).

\section{Animals and experimental diets}

All procedures for the animal experiments were performed in conformance with the guidelines on animal experiments provided set out by the ethical committee of the Animal Welfare Center at the University of the Ryukyus. Eighteen 3-wk-old male C57BL/6 (B6) mice were purchased from Japan SLC, Inc. (Shizuoka, Japan). The mice were housed individually in plastic cages under specific pathogen-free conditions, and maintained at $24^{\circ} \mathrm{C}$ in a $12 \mathrm{~h}$ light-dark cycle. After $1 \mathrm{wk}$ of adaptation, the $\mathrm{B} 6$ mice were randomly divided into 3 experimental HFD groups ( $\mathrm{n}=6$ for each group): a control diet group, a 5\% CL diet group, and a 10\% CL diet group. Experimental HFD containing with 15\% fat were prepared on the basis of AIN-76 formulation-its composition is summarized in Table 1. Approximately $31 \%$ of total calories were derived from fat in HFD used in this study. We prepared the HFD expeditiously in room temperature. Prepared HFD were stored at $-80^{\circ} \mathrm{C}$ in plastic bags with nitrogen gas until use. The mice were fed the experimental HFD and water ad libitum for $4 \mathrm{wk}$. At the end of the feeding period, the mice were killed after $6 \mathrm{~h}$ starvation by exsanguination from the heart under anesthesia induced using pentobarbital sodium salt. Their liver and epididymal, perirenal, omental and waist subcutaneous WATs were excised and serum was separated from the blood. Liver, perirenal and subcutaneous WATs, and sera were frozen immediately in liquid nitrogen and then were stored at $-80^{\circ} \mathrm{C}$ until use. 
Table 1 Composition of the experimental diets

\begin{tabular}{|c|c|c|c|}
\hline \multirow[t]{2}{*}{ Ingredient } & \multicolumn{3}{|c|}{ Diet } \\
\hline & Control & $5 \% \mathrm{CL}$ & $10 \% \mathrm{CL}$ \\
\hline & \multicolumn{3}{|c|}{ (\%) } \\
\hline Casein & 20 & 19.045 & 18.09 \\
\hline$\beta$-Corn starch & 15 & 14.365 & 13.73 \\
\hline Sucrose & 39.4 & 38.485 & 37.49 \\
\hline Cellulose & 5 & 3.11 & 1.22 \\
\hline Mineral mix (AIN-76) & 3.5 & 3.5 & 3.5 \\
\hline Vitamin mix (AIN-76) & 1 & 1 & 1 \\
\hline DL-Methionine & 0.3 & 0.3 & 0.3 \\
\hline Choline bitartrate & 0.2 & 0.2 & 0.2 \\
\hline Corn oil & 15 & 14.735 & 14.47 \\
\hline Water & 5.2 & 2.6 & 0.0 \\
\hline CL powder* & 0 & 5 & 10 \\
\hline Total & 100 & 100 & 100 \\
\hline
\end{tabular}

*Carbohydrate, $12.7 \%$; fiber, $37.8 \%$; mineral $19.9 \%$; protein, $19.1 \%$; fat, $5.3 \%$; moisture, $5.2 \%$.

\section{Measurement of serum biochemical parameters}

Serum levels of TG, total cholesterol (TC), and nonesterified fatty acids (NEFA) were determined by using a commercial enzymatic kit (Wako Pure Chemical Industries, Ltd., Osaka, Japan). The activities of aspartate aminotransferase (AST) and alanine aminotransferase (ALT) in serum were measured by using a commercially available kit (Wako Pure Chemical Industries, Ltd.) Serum levels of insulin and total adiponectin were measured by using ELISA kits that were purchased from Morinaga Institute of Biological Science, Inc. (Kanagawa, Japan) and Otsuka Pharmaceutical Co., Ltd. (Tokyo, Japan), respectively.

\section{Measurement of TG and TC levels in the liver}

Hepatic lipids were extracted and purified according to a method reported previously [19]. Hepatic TG and TC levels were determined by using the method of Fletcher [20] and by using a commercial enzymatic kit as mentioned above, respectively.

\section{RNA extraction and quantitative real-time RT-PCR}

Total RNA was extracted from the cultured cells or the excised tissues by using TRIzol Reagent and a PureLink RNA mini kit (Life technologies). First strand cDNA was synthesized with $2 \mu \mathrm{g}$ of total RNA as a template. The Additional file 1: Table S1 lists the DNA sequences of specific primers that were used for quantitative real-time PCR: $\beta$-actin, $18 \mathrm{~S}$ rRNA, mesoderm-specific transcript (MEST), peroxisome proliferator-activated receptor (PPAR) $\alpha$, PPAR $\gamma$, sterol regulatory element-binding protein (SREBP)-1c, SREBP-2, fatty acid binding protein 4 (FABP4), CCAAT/enhancer binding protein $(\mathrm{C} / \mathrm{EBP}) \alpha$, fatty acid synthase (FASN), insulin receptor (IR), HMG-CoA reductase (HMGCR), calnitine palmitoyltrasferase (CPT)-1A, insulin induced gene (INSIG)-2a, acyl-CoA oxidase (AOX), and uncoupling protein (UCP)-2. The amplifications were performed in a commercial real-time PCR system (StepOne RealTime PCR System; ABI). The relative amount of each gene transcript was normalized to the amount of $\beta$-actin transcript in adipocytes and WAT and to the amount of $18 \mathrm{~S}$ rRNA in the liver.

\section{Statistical analysis}

For in vitro experiments, the statistical significance of the difference between two experimental groups was determined by using Student's $t$-test. The statistical significance of the differences between the mean values of the control and treatment groups were inspected by using Dunnett's test for the animal experiments. Differences were considered significant at $P<0.05$.

\section{Results}

\section{Phenolic content of $\mathrm{CL}$ extracts}

Serial extractions of $\mathrm{CL}$ powder were performed to evaluate their effectiveness in vitro. The yields of the dry material from extracts were as follows (g/100 g CL powder): hexane extract (1.97 g), chloroform extract (2.73 g), ethanol extract $(7.33 \mathrm{~g})$ and water extract $(28.8 \mathrm{~g})$. Of these extracts, the ethanol extract had the highest phenolic content $(618 \mathrm{mg} \mathrm{CA} / \mathrm{g})$. The phenolic content of hexane, chloroform, and water extracts were 26.4, 70.9, and $121 \mathrm{mg} \mathrm{CA} / \mathrm{g}$ extract, respectively.

\section{Effect of CL extracts on 3T3-L1 adipocytes}

The antiadipogenic activities of serial extracts from CL were tested in vitro by using Oil Red $\mathrm{O}$ staining (Figure 1A). Red-stained lipid droplets in differentiated adipocytes were not observed in the non-differentiated 3T3-L1 cells (Figure 1A). Adipogenic differentiation of the 3T3-L1 cells significantly increased their lipid content (Figures 1A and 1B). No significant effect on the lipid content of 3T3-L adipocytes was noted with the chloroform, ethanol, or water extracts of CL powder (Additional file 1: Table S2). However, lipid droplet formation was significantly less in the cells treated with the CL hexane extract than in the control cells. The CL extracts did not affect the cell viability of the differentiated 3T3-L1 adipocytes (data not shown).

\section{Effect of CL hexane extracts on gene expression in 3T3-L1 adipocytes}

To gain more insight into the effects of the CL hexane extract on lipid metabolism, we examined the gene expression of 3T3-L1 adipocytes that were harvested on day 4 of differentiation. The expressions of all of genes that were determined in this study were enhanced by the induction of adipogenesis (Figure 2). Of these, increases 

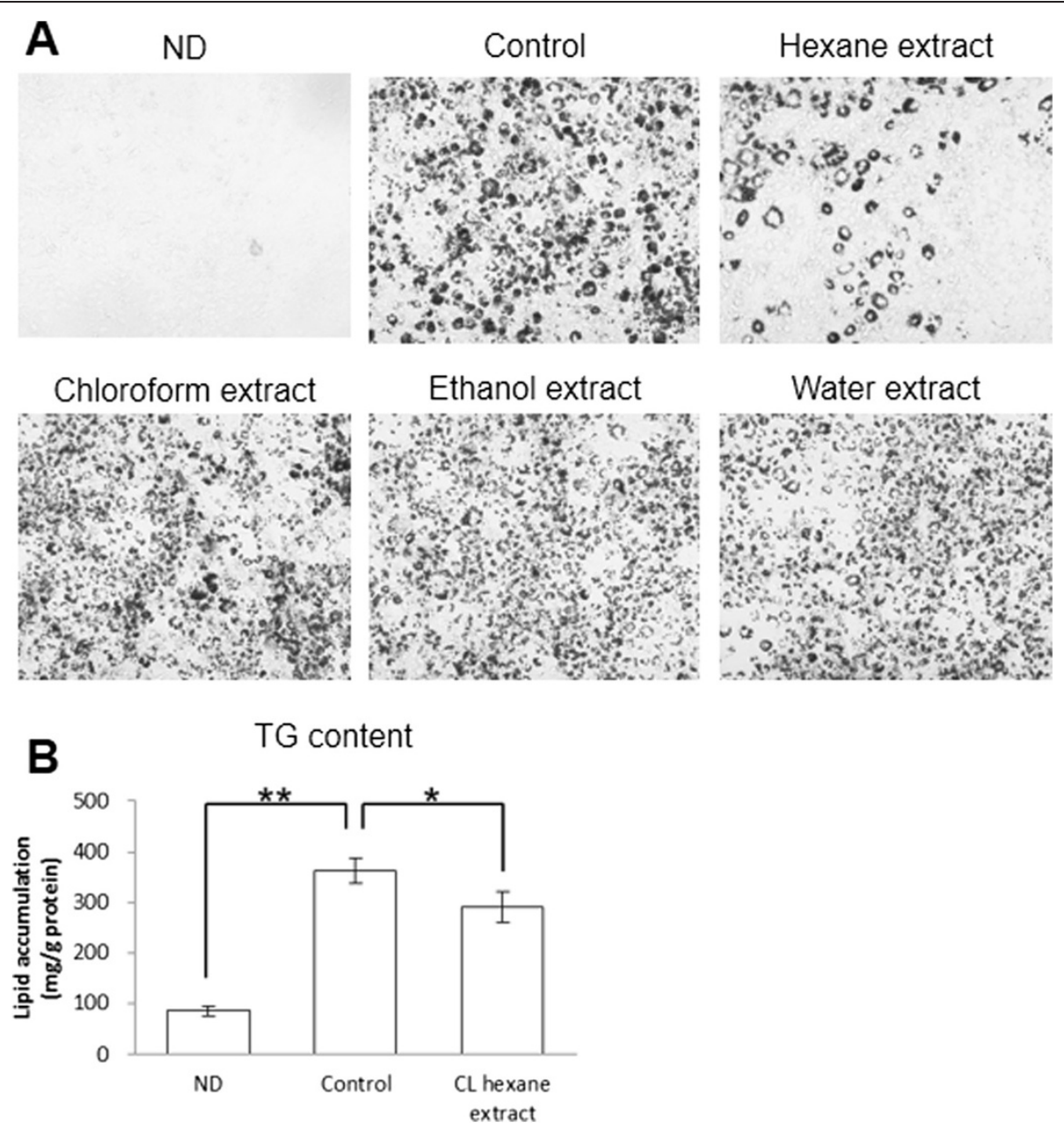

Figure 1 Effects of Cirsium brevicaule A. GRAY leaf (CL) extracts on lipid accumulation in 3T3-L1 adipocytes. (A) Oil red O staining in 3T3L1 cells treated with each $C L$ extract. The data from one representative experiment out of three are shown. (B) Intracellular triglyceride (TG) content of the 3T3-L1 cells. Each value represents as the means \pm SEM for three independent experiments. ND, non-differentiated cells. The asterisks shows significant differences between the experimental groups, determined using Student's t-test (*: $\left.P<0.05,{ }^{*}: P<0.01\right)$.

in MEST, C/EBP $\alpha$ and FASN were significantly inhibited by the CL hexane extract.

\section{Effect of dietary CL on growth, serum, and liver parameters of HFD-fed mice}

Although food intake and final body weight were largely comparable among the experimental groups, the relative liver weights of $5 \%$ or $10 \%$ CL for the diet group were significantly lower than those of control diet group (Table 2). The relative weight of subcutaneous WAT was significantly decreased and that of perirenal WAT tended to decrease in the $10 \% \mathrm{CL}$ diet group compared to the control group. No significant changes were observed in serum levels of TG, TC, glucose, insulin and adiponectin. Serum NEFA levels in the $10 \%$ CL diet group were significantly lower than that in the control diet group. In accordance with the decrease in relative liver weight (Table 2), the hepatic TC levels of the CL diet groups were significantly lower than that of control diet group (Figure 3A). The hepatic TG level was also significantly decreased by $10 \%$ CL diet. A significant decrease in serum AST activity and a decreasing tendency in serum ALT activity were observed for the 10\% CL diet group (Figure 3B).

\section{Effect of dietary CL on gene expression in the WATs of HFD-fed mice}

In subcutaneous and perirenal WAT, expression of the FASN gene was significantly reduced by both $5 \%$ and $10 \%$ CL diets (Figure 4). Similarly, the C/EBP $\alpha$ mRNA levels were decreased by CL diets.

\section{Effect of dietary CL on gene expression in the livers of HFD-fed mice}

Hepatic mRNA levels of the FASN gene were significantly decreased in the CL diet groups (Figure 5). Significant decreases in HMGCR and INSIG-2a expressions were also 

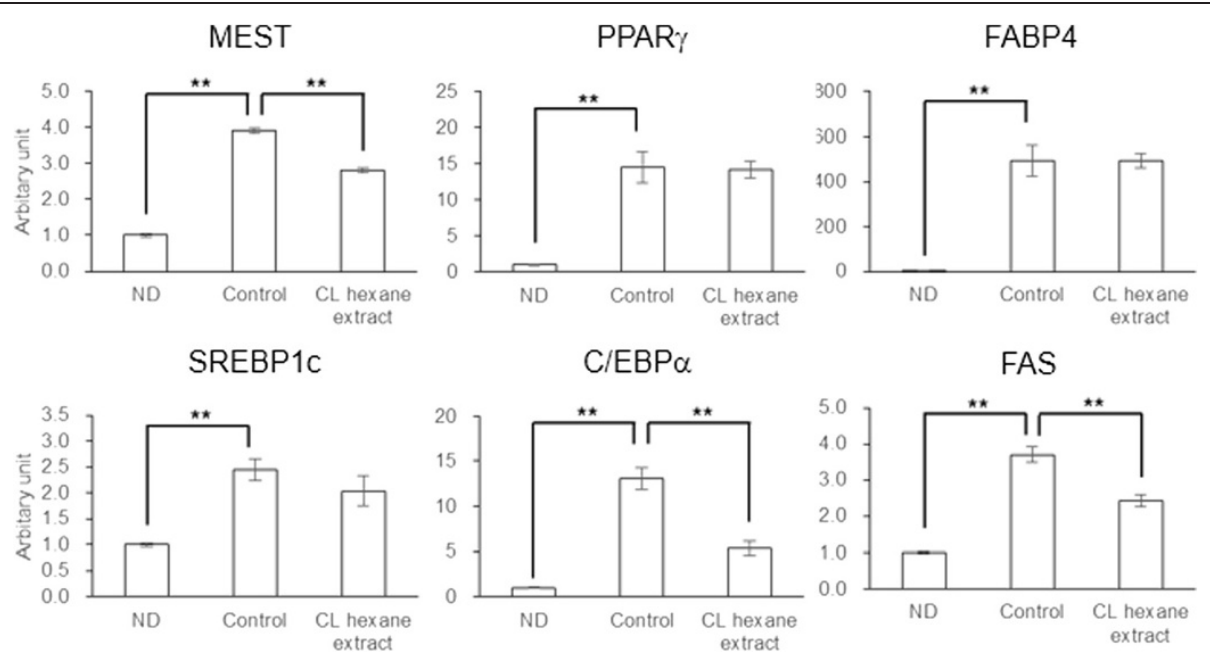

Figure 2 Effect of Cirsium brevicaule A. GRAY leaf (CL) hexane extract on gene expression in 3T3-L1 cells. Each value represents the means \pm S.E.M. for three independent experiments. ND, non-differentiated cells. The asterisks shows significant differences between the experimental groups, determined using Student's t-test $(*: P<0.05, * *: P<0.01)$.

observed in the livers of mice fed a $10 \% \mathrm{CL}$ diet. In contrast, mRNA levels of CPT1A, UCP2, IR, and SREBP-2 were significantly increased by the $10 \% \mathrm{CL}$ diet. AOX gene expression was largely comparable among the experimental groups.

\section{Discussion}

We investigated for the first time the effects of CL extracts on adipogenesis in adipocytes, and on the development of obesity in B6 mice that are fed a HFD. The CL hexane extract inhibited lipid accumulation and downregulated FASN expression in 3T3-L1 cells (Figures 1 and 2). Dietary $\mathrm{CL}$ also suppressed lipid accumulation as well as FASN mRNA levels in subcutaneous WAT and the livers of mice fed a HFD (Table 2, Figures 4 and 5). Dietary CL, on the other hand, increased in the hepatic mRNA levels of genes related to $\beta$-oxidation. These results suggest that $C L$ exerts the antiobesity effects partly through downregulation of fatty acid biosynthesis and enhancement of lipolysis.

FASN is highly expressed in adipose tissue and the liver. This enzyme activity is mostly regulated at the transcriptional level [21]. It has been demonstrated that FASN inhibitors such as C75 significantly suppress the differentiation and lipid accumulation in 3T3-L1 cells, which suggests that FASN plays an essential role supporting the differentiation of preadipocytes [17]. Transcription factors such as SREBP-1c, C/EBP $\alpha$, and PPAR $\gamma$ are known to control the FASN expression [22,23]. In this study, the treatment of 3T3-L1 cells with CL hexane extract significantly decreased their TG content (Figure 1) and MEST gene expression (Figure 2), which could be a novel marker for adipocyte size [24]. Significant decreases in C/EBP $\alpha$ and FASN gene expressions, which were observed with
Table 2 Effect of dietary CBAG leaf on growth and serum parameters in mice

\begin{tabular}{lccc}
\hline Parameters & \multicolumn{3}{c}{ Group } \\
\cline { 2 - 4 } & Control diet & $\mathbf{5 \%}$ CL diet & $\mathbf{1 0 \%}$ CL diet \\
\hline Food Intake (g/day) & $2.25 \pm 0.01$ & $2.22 \pm 0.04$ & $2.24 \pm 0.03$ \\
Initial body weight (g) & $13.9 \pm 0.32$ & $13.7 \pm 0.27$ & $13.7 \pm 0.28$ \\
Final body weight $(\mathrm{g})$ & $25.7 \pm 0.43$ & $24.8 \pm 0.54$ & $24.5 \pm 0.40$ \\
Liver weight (g/100 g & $4.50 \pm 0.11$ & $3.88 \pm 0.17^{*}$ & $3.67 \pm 0.12^{* *}$ \\
body weight) & & &
\end{tabular}

White adipose tissue weight (g/100 g body weight)

$\begin{array}{lccc}\text { Total }^{\dagger} & 6.03 \pm 0.47 & 5.75 \pm 0.36 & 5.26 \pm 0.28 \\ \text { Abdominal }^{\S} & 4.34 \pm 0.35 & 4.36 \pm 0.31 & 4.00 \pm 0.22 \\ \text { Epididymal } & 2.18 \pm 0.16 & 2.13 \pm 0.16 & 1.98 \pm 0.11 \\ \text { Perirenal } & 0.81 \pm 0.14 & 0.80 \pm 0.07 & 0.64 \pm 0.06 \\ \text { Omental } & 1.35 \pm 0.08 & 1.44 \pm 0.10 & 1.37 \pm 0.08 \\ \text { Subcutaneous } & 1.69 \pm 0.12 & 1.39 \pm 0.06 & 1.26 \pm 0.08^{* *} \\ \text { Serum parameters } & & & \\ \text { Triglyceride (mg/dL) } & 35.0 \pm 3.41 & 40.5 \pm 3.71 & 32.2 \pm 3.10 \\ \text { Total cholesterol (mg/dL) } & 107 \pm 4 & 107 \pm 4 & 114 \pm 3 \\ \text { Non-esterified fatty acid } & 9.68 \pm 0.89 & 8.41 \pm 0.40 & 6.56 \pm 0.56^{* *} \\ \text { (mEq/dL) } & & & \\ \text { Glucose (mg/dL) } & 210 \pm 11 & 242 \pm 11 & 211 \pm 25 \\ \text { Insulin (ng/mL) } & 1.70 \pm 0.23 & 1.74 \pm 0.18 & 1.79 \pm 0.31 \\ \text { Adiponectin (ng/mL) } & 3.58 \pm 0.11 & 3.51 \pm 0.15 & 3.30 \pm 0.13\end{array}$

Each value represents as the means \pm S.E.M. for six mice. ${ }^{\dagger}$ Total white adipose tissue weight represents the sum of abdominal and subcutaneous white adipose tissue weights. ${ }^{\S} \mathrm{Abdominal}$ white adipose tissue weight represents the sum of epididymal, perirenal and omental white adipose tissue weights. Asterisk shows significant differences when compared to the control group by Dunnett's test $\left({ }^{*}: P<0.05,{ }^{* *}: P<0.01\right)$. 


\section{A Hepatic Total Cholesterol}

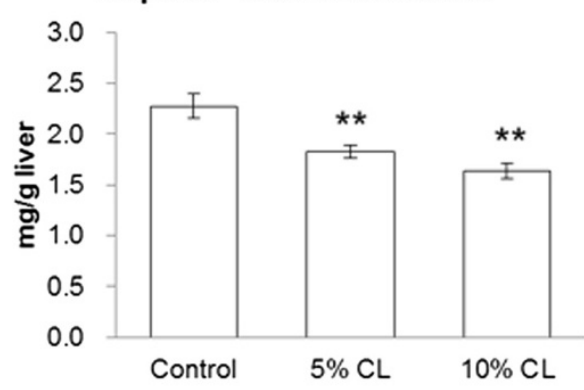

B

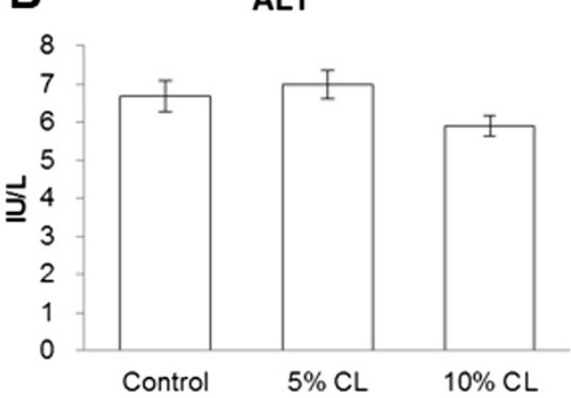

Hepatic Triglycerides

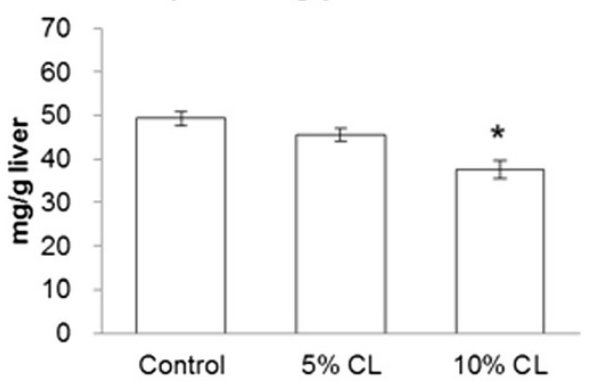

AST

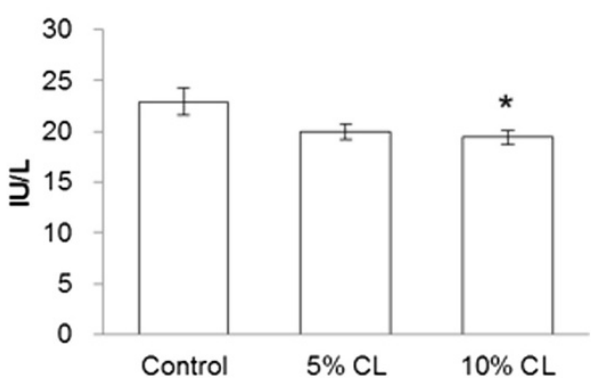

Figure 3 Effect of dietary Cirsium brevicaule A. GRAY leaf (CL) on hepatic physiological parameters in mice. (A) Serum lipid levels.

(B) Serum levels of hepatopathic indicator. Each value represents the means \pm S.E.M. for six mice. The asterisk shows significant differences when compared to the control group, determined using Dunnett's test (*: $P<0.055^{* *}: P<0.01$ ).

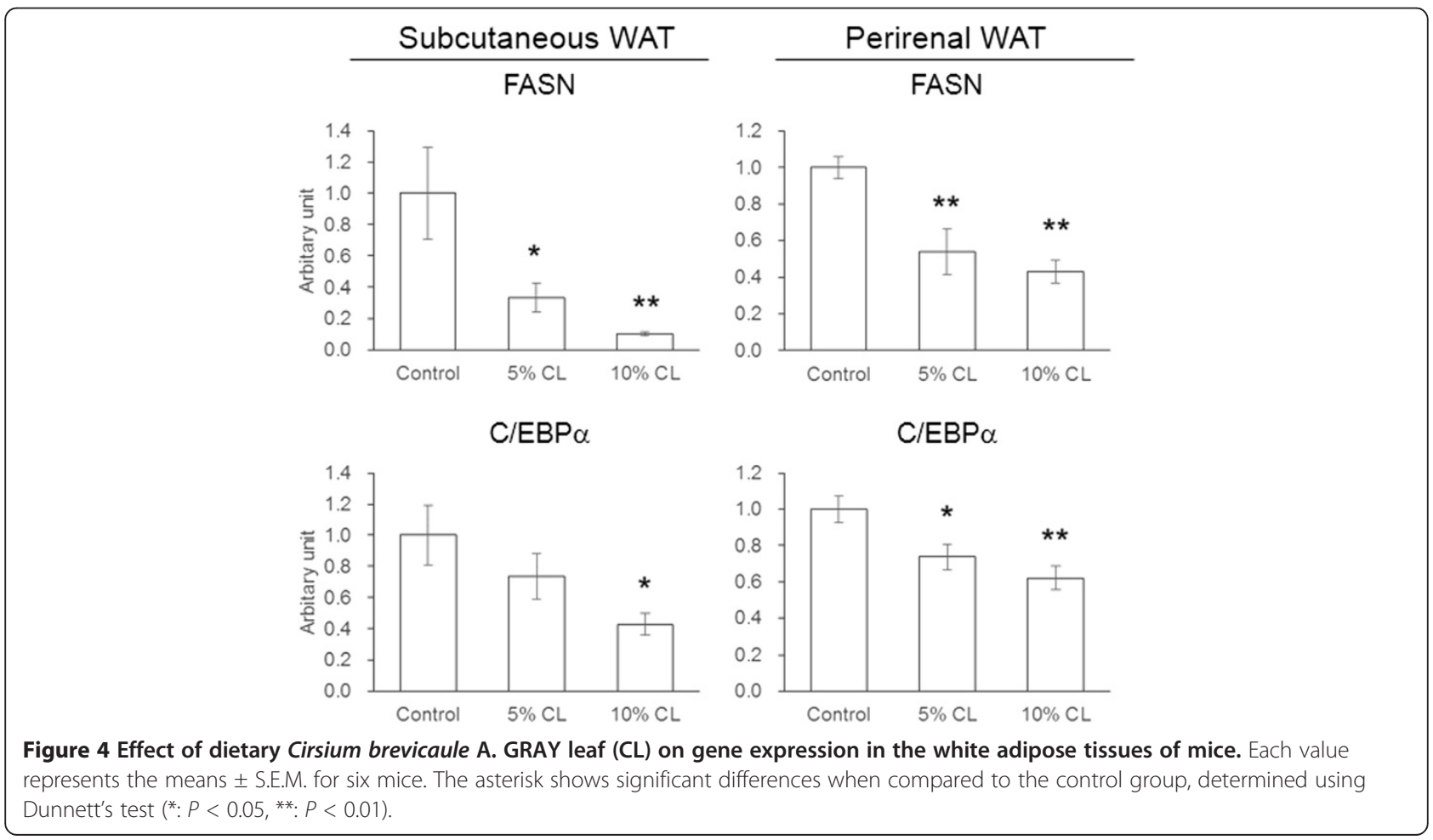




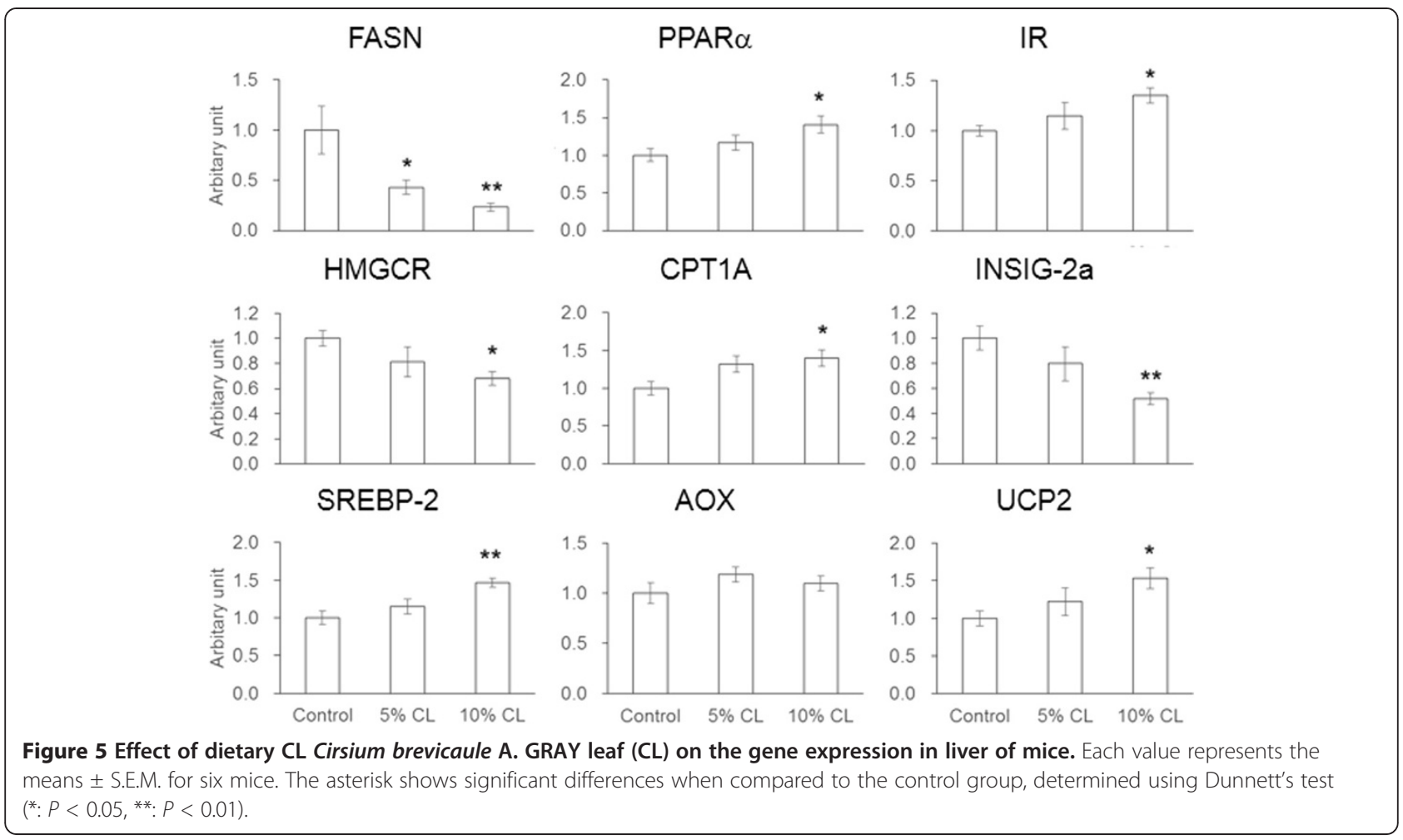

the CL hexane treatment were not necessarily associated with changes in the mRNA levels of SREBP-1c as well as PPAR $\gamma$ and its target gene FABP4. Dietary CL induced a significant reduction or caused a decreasing trend in the WAT weight of the HFD-fed mice (Table 2). Furthermore, the expressions of FASN and C/EBP $\alpha$ in WATs were significantly decreased by the CL diet (Figure 4). These results suggest that the chemical component in $\mathrm{CL}$ suppressed adipogenic differentiation or lipid accumulation in adipocytes through the inhibition of FASN gene expression via the downregulation of C/EBP $\alpha$.

In humans, since exogenous saturated fatty acids are available abundantly through the daily diet, it was considered that de novo synthesis of fatty acids was negligible [25]. However, liver-selective FASN inhibition by platensimycin could lead to improved hepatic steatosis and T2DM in model mice [26]. This observation provided the pharmacological proof of concept of FASN inhibition as a unique treatment for obesity-related disorders. In this study, significant decreases in FASN expression in WATs and the liver were observed in the CL-fed mice (Figures 3 and 5). PPAR $\alpha$ is well known as an indispensable regulator of liver lipid metabolism. The key enzymes involved in fatty acid oxidation such as CPT1A and AOX are mainly regulated by PPAR $\alpha[27,28]$. Furthermore, PPAR $\alpha$ induces UCP2 upregulation, which is involved in the regulation of energy expenditure [29]. The $10 \% \mathrm{CL}$ diet significantly increased the mRNA levels of PPAR $\alpha$, CPT1A and UCP2, but not AOX (Figure 5). Therefore, these results suggest that dietary CL suppressed hepatic TG content through inhibition of FASN expression and enhancement of fatty acid oxidation, thereby leading to significant reductions in serum NEFA levels in the HFD-fed mice (Table 2). Plasma NEFA levels are elevated in obesity, and a high level of NEFA is considered a critical factor that triggers the onset of peripheral and hepatic insulin resistance [30], eventually leading to development of metabolic syndrome including T2DM and NAFLD. NEFA were recently highlighted to play primary roles in the pathogenesis of NAFLD by inducing inflammation, oxidative stress, apoptosis, and cytokine production in hepatocytes [31].

IR is as known as one of the most important molecules involved in NEFA-induced insulin resistance, because fatty acids suppress the protein and mRNA levels of IR in muscle cells and hepatic cells [32,33]. Although serum insulin levels were largely comparable among the experimental groups in the present study (Table 2), IR gene expression was significantly increased in the liver of mice fed the $10 \% \mathrm{CL}$ diet (Figure 5). Yabe et al. [34] discovered a liver-specific transcript of INSIG-2, designated INSIG-2a, which is downregulated by insulin. Our study showed that the hepatic mRNA level of INSIG-2a in the 10\% CL diet group was significantly lower than that in control diet group (Figure 5). Thus, dietary CL likely functions to restore hepatic insulin sensitivities in HFDfed mice, preventing the development of NAFLD. In contrast, Insigs is known to negatively regulate HMGCR transcription by suppressing the activation of SREBPs 
[35]. SREBP-2 promotes the mRNA transcription of cholesterol biosynthesis-related genes including HMGCR [36]. A significant increase in SREBP-2 gene expression was herein observed in the livers of the $10 \% \mathrm{CL}$ diet group (Figure 5), although the mRNA level of HMGCR was significantly decreased. These conflicting results need further clarification to fully understand the anti-obesity activity of CL.

Few studies examined the phenolic compounds in CBAG, although various phenolic compounds have been isolated from the genus Cirsium. Pectolinarin have been reported as a major flavonoid in Japanese Cirsium species [37], and it was isolated from CBAG [38]. Apigenin, linarin, and luteorin were also isolated from a wide variety of Cirsium species [39]. Treatment of 3T3-L1 cells with pectolinarin were significantly increased cellular TG content [11]. Apigenin, but not luteorin, significantly inhibited adipogenesis in 3T3-L1 cells [40]. Although many phenolic compounds have been reported to inhibit lipid accumulation in 3T3-L1 cells [41], the hexane extract of the lowest phenolic content among CL extracts herein inhibited lipid accumulation in 3T3-L1 cells (Figure 1B and Additional file 1: Table S2). This finding suggests that the anti-obesity activity of $\mathrm{CL}$ is associated with more hydrophobic non-phenolic compounds. Further purification and identification of active component(s) in $\mathrm{CL}$ would be necessary.

Liao et al. [11,12] reported that pectolinarin and DDMF, which are flavonoids isolated from C. japonicum DC, enhance adipogenic differentiation of 3T3-L1 cells and alleviate streptozotocin-induced diabetes through enhanced PPARy expression and adiponectin production. Crude extracts prepared from C. oligophyllum significantly suppressed the lipid accumulation in WATs by upregulating UCP1 and UCP3 expression in WATs and skin, respectively [13]. In our present study, the hexane extract inhibited adipocyte development and TG accumulation in 3T3-L1 cells with no change in PPAR $\gamma$ gene expression (Figures $1 \mathrm{~B}$ and 2). Dietary $\mathrm{CL}$ reduced the WAT weights without any changes in serum adiponectin levels (Table 2). An inhibition of intestinal TG absorption generally decreased blood TG level, and a similar result is observed with cholesterol [42]. In the present study, significant decrease in serum NEFA level were observed but not in TG and cholesterol levels of CL-fed mice (Table 2). Therefore, the reduction in the adipose tissue weight may be explained by the decreased endogenous NEFA supply for adipogenesis and the enhancement of fatty acid oxidation. Significant changes in the mRNA levels of lipid metabolism-related genes and the lipid content in the livers of the CL diet group appear to support this hypothesis. However, these data do not necessarily negate the possibility that CL interfered the lipid absorption, and thereby exerted the anti-obesity activity as was the case in the previous studies. Further studies are needed to address this question.

\section{Conclusion}

The present results clearly demonstrated the presence of antiobesity phytochemicals in CL, thereby providing scientific evidence to promote the development of natural and safe antiobesity agents from CL. The components in $\mathrm{CL}$ remains to be identified, and further studies should be conducted to gain insights into the mechanism of action of CL.

\section{Additional file}

Additional file 1: Table S1. Primer sequences for real time PCR amplification. Table S2. Effects of Cirsium brevicaule A. GRAY leaf (CL) extracts on lipid accumulation in 3T3-L1 adipocytes.

\section{Abbreviations}

ALT: Alanine aminotransferase; AST: Aspartate aminotransferase; AOX: AcylCoA oxidase; B6: C57BL/6; CBAG: Cirsium brevicaule A GRAY; C/EBP: CCAAT/ enhancer binding protein; CL: CBAG leaf; CPT: Calnitine palmitoyltrasferase; DDMF: 5, 7-dihydroxy-6, 4'-dimethoxyflavone; FABP: Fatty acid binding protein; FASN: Fatty acid synthase; HFD: High fat diet; INSIG: Insulin induced gene; IR: Insulin receptor; MEST: Mesoderm-specific transcript;

NAFLD: Nonalcoholic fatty liver disease; NEFA: Non-esterified fatty acids; PPAR: Peroxisome proliferator-activated receptor; SREBP: Sterol regulatory element-binding protein; TC: Total cholesterol; TG: Triglyceride; T2DM: Type 2 diabetes mellitus; UCP: Uncoupling protein; WAT: White adipose tissue.

\section{Competing interests}

The authors declare that they have no competing interests.

\section{Authors' contributions}

MI made a substantial contribution to the conception and design of this study by performing the experiments, assembling, analyzing, and interpreting the data and drafting the manuscript. RN, IF, and Al participated in the experimental work and collected, assembled, and analyzed the data. YK contributed to the conception of this study and the preparation of the materials for the experiments. $\mathrm{HO}$ contributed to planning the experiments, discussing the results, and preparing the manuscript. All of the authors have read and approved of the final manuscript.

\section{Acknowledgements}

We thank Tokunoshima-cho in Kagoshima Prefecture, Japan, for generously providing the freeze-dried and ground powder of $\mathrm{CL}$ that was used in this study.

\section{Author details}

${ }^{1}$ Center of Molecular Biosciences, Tropical Biosphere Research Center, University of the Ryukyus, 1 Senbaru, Nishihara, Okinawa 903-0213, Japan. ${ }^{2}$ United Graduate School of Agricultural Sciences, Kagoshima University, 1-21-24 Korimoto, Kagoshima 890-0065, Japan. ${ }^{3}$ Tokunoshima Tokushukai Hospital, 7588 Kametsu, Tokunoshima, Kagoshima 891-7101, Japan.

Received: 8 July 2013 Accepted: 14 August 2013

Published: 15 August 2013

\section{References}

1. Kissebah $\mathrm{AH}$, Krakower GR: Regional adiposity and morbidity. Physiol Rev 1994, 74(4):761-811.

2. Formiguera $X$, Canton A: Obesity: epidemiology and clinical aspects. Best Pract Res Clin Gastroenterol 2004, 18(6):1125-1146.

3. Fan JG, Li F, Cai XB, Peng YD, Ao QH, Gao Y: Effects of nonalcoholic fatty liver disease on the development of metabolic disorders. $J$ Gastroenterol Hepatol 2007, 22(7):1086-1091. 
4. Youssef W, McCullough AJ: Diabetes mellitus, obesity, and hepatic steatosis. Semin Gastrointest Dis 2002, 13(1):17-30.

5. Alemany M, Remesar X, Fernandez-Lopez JA: Drug strategies for the treatment of obesity. IDrugs 2003, 6(6):566-572

6. Lafontan M, Langin D: Lipolysis and lipid mobilization in human adipose tissue. Prog Lipid Res 2009, 48(5):275-297.

7. Galleano M, Calabro V, Prince PD, Litterio MC, Piotrkowski B, Vazquez-Prieto MA, Miatello RM, Oteiza PI, Fraga CG: Flavonoids and metabolic syndrome Ann N Y Acad Sci 2012, 1259:87-94.

8. Iwashina T, Kamenosono T, Ueno T: Hispidulin and nepetin 4'-glucosides from Cirsium oligophyllum. Phytochemistry 1999, 51(8):1109-1111.

9. Iwashina T, Kadota Y, Ueno T, Ootani S: Foliar flavonoid composition in Japanese Ciusium species (Compositae), and their chemotaxonomic significance. J Japanese Bot 1995, 70:280-290.

10. Liu S, Luo X, Li D, Zhang J, Qiu D, Liu W, She L, Yang Z: Tumor inhibition and improved immunity in mice treated with flavone from Cirsium japonicum DC. Int Immunopharmacol 2006, 6(9):1387-1393.

11. Liao Z, Wu Z, Wu M: Cirsium japonicum flavones enhance adipocyte differentiation and glucose uptake in 3T3-L1 cells. Biol Pharm Bull 2012, 35(6):855-860

12. Liao $Z$, Chen $X$, Wu M: Antidiabetic effect of flavones from Cirsium japonicum DC in diabetic rats. Arch Pharm Res 2010, 33(3):353-362.

13. Mori S, Satou M, Kanazawa S, Yoshizuka N, Hase T, Tokimitsu I, Takema Y, Nishizawa Y, Yada T: Body fat mass reduction and up-regulation of uncoupling protein by novel lipolysis-promoting plant extract. Int I Biol Sci 2009, 5(4):311-318.

14. Perez Gutierrez RM, Ramirez E, Vargas R: Effect of Cirsium pascuarense on blood glucose levels of normoglycaemic and alloxan-diabetic mice. Phytother Res 2001, 15(6):552-554.

15. Kadawaki Y: Taxonomy and distribution of Cirsium brevicaule A. GRAY and its related species (Asteraceae). Mem Natn Sci Mus, Tokyo 1990, 23:51-61.

16. Inafuku M, Toda T, Okabe T, Wada K, Takara K, Iwasaki H, Oku H: Effect of Kokuto, a non-centrifugal cane sugar, on the development of experimental atherosclerosis in Japanese quail and apolipoprotein $\mathrm{E}$ deficient mice. Food Sci Technol Res 2007, 13(1):61-66.

17. Schmid B, Rippmann JF, Tadayyon M, Hamilton BS: Inhibition of fatty acid synthase prevents preadipocyte differentiation. Biochem Biophys Res Commun 2005, 328(4):1073-1082.

18. Bligh EG, Dyer WJ: A rapid method of total lipid extraction and purification. Can J Biochem Physiol 1959, 37(8):911-917

19. Folch J, Lees $M$, Sloane Stanley GH: A simple method for the isolation and purification of total lipides from animal tissues. J Biol Chem 1957, 226(1):497-509.

20. Fletcher MJ: A colorimetric method for estimating serum triglycerides. Clin Chim Acta 1968, 22(3):393-397.

21. Radenne A, Akpa M, Martel C, Sawadogo S, Mauvoisin D, Mounier C: Hepatic regulation of fatty acid synthase by insulin and T3: evidence for T3 genomic and nongenomic actions. Am J Physiol Endocrinol Metab 2008, 295(4):E884-E894.

22. Mandrup S, Lane MD: Regulating adipogenesis. J Bio/ Chem 1997 272(9):5367-5370.

23. Sul HS, Latasa MJ, Moon Y, Kim KH: Regulation of the fatty acid synthase promoter by insulin. J Nutr 2000, 130(2S Suppl):315S-320S

24. Takahashi M, Kamei Y, Ezaki O: Mest/Peg1 imprinted gene enlarges adipocytes and is a marker of adipocyte size. Am J Physiol Endocrinol Metab 2005, 288(1):E117-E124.

25. Weiss L, Hoffmann GE, Schreiber R, Andres H, Fuchs E, Korber E, Kolb HJ: Fatty-acid biosynthesis in man, a pathway of minor importance. Purification, optimal assay conditions, and organ distribution of fattyacid synthase. Biol Chem Hoppe Seyler 1986, 367(9):905-912.

26. Wu M, Singh SB, Wang J, Chung CC, Salituro G, Karanam BV, Lee SH, Powles M, Ellsworth KP, Lassman ME, et al: Antidiabetic and antisteatotic effects of the selective fatty acid synthase (FAS) inhibitor platensimycin in mouse models of diabetes. Proc Natl Acad Sci U S A 2011, 108(13):5378-5383.

27. Ip E, Farrell GC, Robertson G, Hall P, Kirsch R, Leclercq I: Central role of PPARalpha-dependent hepatic lipid turnover in dietary steatohepatitis in mice. Hepatology 2003, 38(1):123-132

28. Huang $H$, Mclntosh AL, Martin GG, Petrescu AD, Landrock KK, Landrock D, Kier $A B$, Schroeder F: Inhibitors of fatty acid synthesis induce PPAR alpha - regulated fatty acid beta -oxidative genes: synergistic roles of L-FABP and glucose. PPAR Res 2013, 2013:865604

29. Nakatani T, Tsuboyama-Kasaoka N, Takahashi M, Miura S, Ezaki O: Mechanism for peroxisome proliferator-activated receptor-alpha activator-induced up-regulation of UCP2 mRNA in rodent hepatocytes. J Biol Chem 2002, 277(11):9562-9569.

30. Boden G: Role of fatty acids in the pathogenesis of insulin resistance and NIDDM. Diabetes 1997, 46(1):3-10.

31. Chavez-Tapia NC, Rosso N, Tiribelli C: Effect of intracellular lipid accumulation in a new model of non-alcoholic fatty liver disease. BMC Gastroenterol 2012, 12:20.

32. Dey D, Bhattacharya A, Roy S, Bhattacharya S: Fatty acid represses insulin receptor gene expression by impairing HMGA1 through protein kinase Cepsilon. Biochem Biophys Res Commun 2007, 357(2):474-479.

33. Ruddock MW, Stein A, Landaker E, Park J, Cooksey RC, McClain D, Patti ME: Saturated fatty acids inhibit hepatic insulin action by modulating insulin receptor expression and post-receptor signalling. J Biochem 2008, 144(5):599-607.

34. Yabe D, Komuro R, Liang G, Goldstein JL, Brown MS: Liver-specific mRNA for Insig-2 down-regulated by insulin: implications for fatty acid synthesis. Proc Natl Acad Sci U S A 2003, 100(6):3155-3160.

35. Dong $X Y$, Tang SQ: Insulin-induced gene: a new regulator in lipid metabolism. Peptides 2010, 31(11):2145-2150.

36. Horton JD, Goldstein JL, Brown MS: SREBPs: activators of the complete program of cholesterol and fatty acid synthesis in the liver. $J$ Clin Invest 2002, 109(9):1125-1131.

37. Iwashina T, Ito T, Ootani S: Identification and peculiarity of flavonoid compounds in leaves of Japanese Circium species. Ann Tsukuba Bot Gard 1988, 7:149-158.

38. Morita N, Fukuta M, Shimizu M: Studies on the Medicinal Resources. XXIII: Flavonoids of Cirsium plants (Compositae) in Japan. (4). Components of the leaves of Cirsium microspicatum NAKAI var. kiotoense KITAM., C, dipsacolepis MATSUM., C. brevicaule A. GRAY, C. Matsumurae NAKAI, C. yakusimense MASAMUNE, C. amplexifolium KITAM., C. buergeri MIQ., C. nipponicum MAKINO var. Yoshinoi KITAM., C. spinosum KITAM., C. tanakae MATSUM. subsp. aomorense KITAM. and C. arvense SCOP, var. setosum LEDEB. Jap J Pharmacognosy 1964, 18(1):9-11.

39. Jordon-Thaden IE, Louda SA: Chemistry of Cirsium and Carduus: a role in ecological risk assessment for biological control of weeds? Biochem Syst Ecol 2003, 31(12):1353-1396.

40. Kim J, Lee I, Seo J, Jung M, Kim Y, Yim N, Bae K: Vitexin, orientin and other flavonoids from Spirodela polyrhiza inhibit adipogenesis in 3T3-L1 cells. Phytother Res 2010, 24(10):1543-1548.

41. Hsu CL, Yen GC: Phenolic compounds: evidence for inhibitory effects against obesity and their underlying molecular signaling mechanisms. Mol Nutr Food Res 2008, 52(1):53-61.

42. Ros E: Intestinal absorption of triglyceride and cholesterol. Dietary and pharmacological inhibition to reduce cardiovascular risk. Atherosclerosis 2000, 151(2):357-379.

doi:10.1186/1476-511X-12-124

Cite this article as: Inafuku et al: Cirsium brevicaule A. GRAY leaf inhibits adipogenesis in 3T3-L1 cells and C57BL/6 mice. Lipids in Health and Disease 2013 12:124.

\section{Submit your next manuscript to BioMed Central and take full advantage of:}

- Convenient online submission

- Thorough peer review

- No space constraints or color figure charges

- Immediate publication on acceptance

- Inclusion in PubMed, CAS, Scopus and Google Scholar

- Research which is freely available for redistribution 